\title{
Metabolic profiling of laser microdissected vascular bundles of Arabidopsis thaliana Martina Schad ${ }^{1}$, Rajsree Mungur ${ }^{1}$, Oliver Fiehn² and Julia Kehr*1
}

Address: ${ }^{1}$ Max-Planck-Institute of Molecular Plant Physiology, Department Lothar Willmitzer, 14424 Potsdam, Germany and ${ }^{2}$ UC Davis, 4321 GBSF Building Health Sciences Drive, Davis (CA) 95616, USA

Email: Martina Schad - schad@mpimp-golm.mpg.de; Rajsree Mungur - mungur@mpimp-golm.mpg.de; Oliver Fiehn - ofiehn@ucdavis.edu; Julia Kehr* - kehr@mpimp-golm.mpg.de

* Corresponding author

Published: 18 August 2005

Plant Methods 2005, I:2 doi:10.1 186/1746-48|I-I-2
Received: 26 May 2005

Accepted: 18 August 2005

This article is available from: http://www.plantmethods.com/content/I/I/2

(C) 2005 Schad et al; licensee BioMed Central Ltd.

This is an Open Access article distributed under the terms of the Creative Commons Attribution License (http://creativecommons.org/licenses/by/2.0), which permits unrestricted use, distribution, and reproduction in any medium, provided the original work is properly cited.

\begin{abstract}
Background: Laser microdissection is a useful tool for collecting tissue-specific samples or even single cells from animal and plant tissue sections. This technique has been successfully employed to study cell type-specific expression at the RNA, and more recently also at the protein level. However, metabolites were not amenable to analysis after laser microdissection, due to the procedures routinely applied for sample preparation. Using standard tissue fixation and embedding protocols to prepare histological sections, metabolites are either efficiently extracted by dehydrating solvents, or washed out by embedding agents.
\end{abstract}

Results: In this study, we used cryosectioning as an alternative method that preserves sufficient cellular structure while minimizing metabolite loss by excluding any solute exchange steps. Using this pre-treatment procedure, Arabidopsis thaliana stem sections were prepared for laser microdissection of vascular bundles. Collected samples were subsequently analyzed by gas chromatography-time of flight mass spectrometry (GC-TOF MS) to obtain metabolite profiles. From 100 collected vascular bundles ( $\sim 5,000$ cells), 68 metabolites could be identified. More than half of the identified metabolites could be shown to be enriched or depleted in vascular bundles as compared to the surrounding tissues.

Conclusion: This study uses the example of vascular bundles to demonstrate for the first time that it is possible to analyze a comprehensive set of metabolites from laser microdissected samples at a tissue-specific level, given that a suitable sample preparation procedure is used.

\section{Background}

Unlike unicellular organisms, plants and animals have evolved as complex organisms that are defined by distributing special vital functions to spatially separated organs and tissues. The distinct functions of tissues and organs result from the integrated activity of individual cells. Cur- rent approaches mostly ignore this fact by analyzing samples that consist of a variety of different cell types and thus average and dilute the information obtained. Parameters that define the function and the physiological state of cells include gene and protein expression, but also the complement of low-molecular-weight compounds such as lipids, 
carbohydrates, vitamins or hormones that carry out much of the cell's business. Therefore, in addition to transcriptomic and proteomic studies, a comprehensive metabolite analysis with high spatial resolution is essential to fully characterize the state of a certain tissue.

To achieve this, analysis of small solutes in individual plant cells has so far been performed after extracting picoliter-sized samples with glass microcapillaries [1] and specialized techniques have been developed to access the ingredients of such small-scale samples [2-5]. However, these techniques remained labor-intensive and require specialized skills and training.

The recent development of methods that allow the collection of enough individual cells to process with standard analytical methods is a key step to integrate high spatial resolution analysis into routine laboratory work. Laser microdissection (LM) $[6,7]$ is meanwhile well-established with animal and human samples and allows the investigation of RNAs and proteins from specific cell types $[8,9]$. Recently, also plants have been successfully used in such experiments and information about gene [10-12] as well as protein expression [13] was obtained.

Before any tissue can be microdissected, histological sections have to be prepared. To this end the tissue is normally fixed and subsequently either embedded in paraffin $[14,15]$ or cryosectioned [15-17]. However, the fixation and dehydration steps included in these procedures lead to an inevitable loss of small cellular components. Therefore, the resulting tissue sections do not allow measurements of the cellular distribution of metabolites and other low-molecular-weight compounds.

The intention of the current study was to develop a tissue processing procedure that enables tissue-specific measurements of metabolites in laser microdissected vascular bundle samples from A. thaliana stems with well-established metabolic profiling techniques. A combination of metabolite profiles with the already established gene and protein expression analysis from microdissected tissue samples will allow a comprehensive description of organisms under different developmental, biotic or abiotic conditions at a tissue-specific level, a further important step towards integrative biology.

\section{Results and discussion}

\section{Preparation and collection of cell type-specific samples}

The most important stage in the analysis of specific tissues or even single cells is the isolation of the target tissue away from adjacent cells. Using microcapillaries is an established option to collect the contents from living plant cells $[1,3,18]$. This sampling technique results not only in very small sample sizes in the picoliter range, but is also lim- ited mainly to surface exposed cells. In this study, we have used laser microdissection (LM) as a powerful alternative sampling method, which allows a contamination-free collection of large homogeneous cell populations also from cells located deep inside the tissue [19].

To date, LM has been widely used, mainly to study cell type-specific gene expression and less frequently for tissue-specific protein analysis in animal tissues $[8,9]$. Recently, this technique was introduced into plant sciences to allow cell type- specific gene expression [10-12] and protein [13] profiling. Laser microdissection coupled to laser pressure catapulting (LMPC) is a method that is applicable to plant material and allows the contact-free collection of specific cells [20]. To perform successful LMPC, dry histological sections with reasonable morphology and cell integrity are needed. While preserving good morphology is required to distinguish the different cell types, it is also crucial to retain the analytes at their in vivo localization. The latter point particularly needs to be considered for the analysis of small substances like metabolites, since it is self-evident that they can easily relocate or get lost during tissue preparation.

In principle, there are two methods for tissue treatment available that are appropriate for subsequent protein or RNA analysis. The first is paraffin-embedding [21-23], which involves numerous steps to fix and dehydrate the tissue, leading to a complete loss of low-molecular-weight compounds. The second option is cryosectioning, which is commonly used to prepare sections for molecular studies of animal tissue, but often downgrades the histological architecture. Plant tissue is particularly prone to cell morphology damage, because ice crystal formation is facilitated in water-rich tissue. To overcome this problem, plant material is usually infiltrated with cryoprotection agents prior to freezing $[11,12]$. But as with paraffin fixation, the use of any solvent in the tissue preparation procedure results in a loss of small substances and makes cell type-specific metabolite profiling unfeasible.

For tissue-specific metabolite profiling of vascular bundles and sections without vascular bundles, we therefore followed the strategy illustrated in Figure 1. We employed a procedure where plant material is frozen without the addition of any protective compounds, and dried without chemical dehydration to avoid the loss or relocalization of small cellular components.

The morphology of the sections obtained from frozen $A$. thaliana stems using a cryostat was reasonable and completely sufficient to selectively excise vascular bundles by LMPC. However, getting decent morphology of stable tissue parts like vascular bundles is less complicated compared to other cell types, and it might also be more 


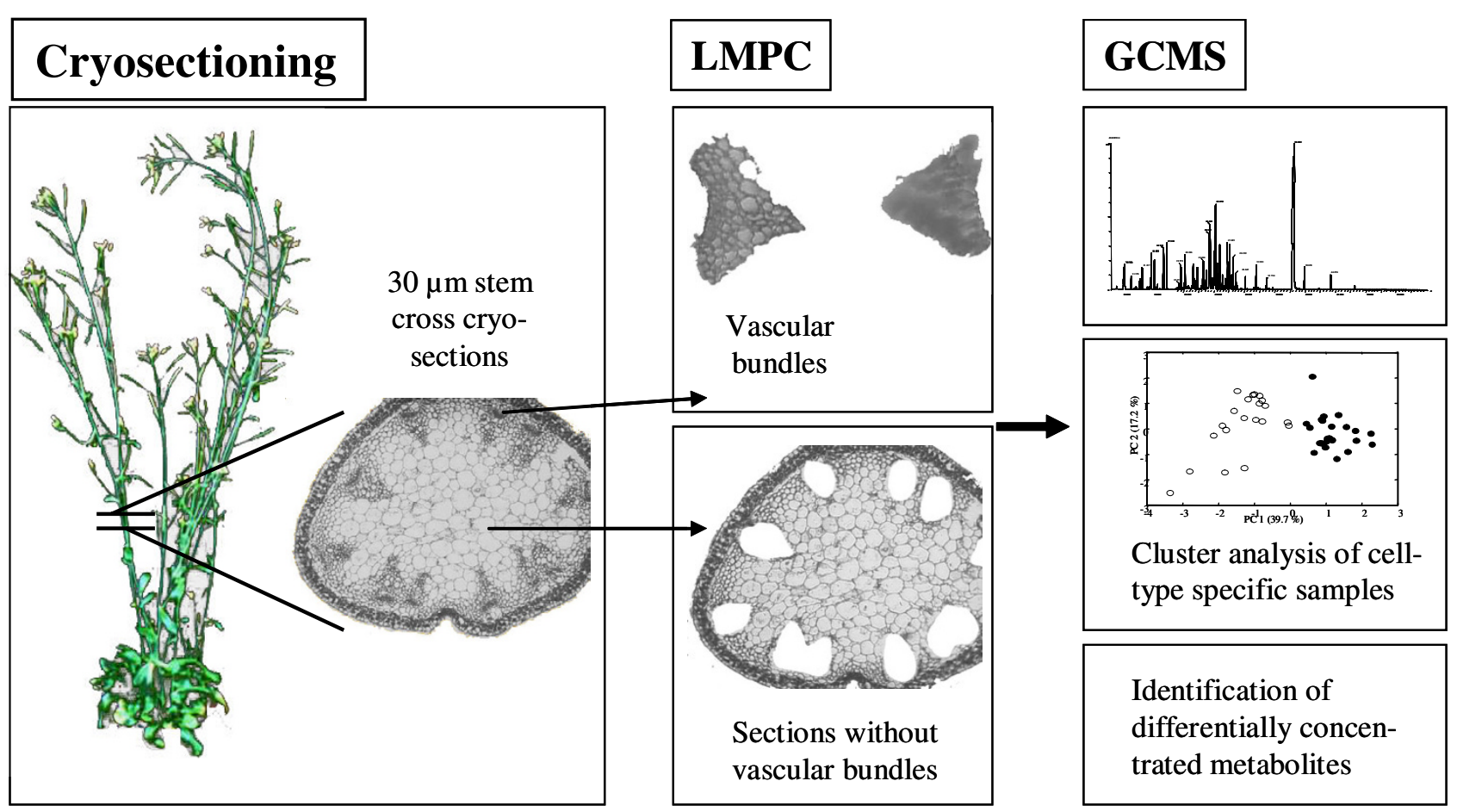

Figure I

Experimental strategy.Outline of the strategy for tissue-specific metabolite profiling in A. thaliana. Stem cross cryosections were used for LMPC. Metabolites from microdissected vascular bundles and sections without vascular bundles, respectively, were extracted and analyzed by GCMS measurements.

difficult to attain cryosections from more delicate plant organs like leaves or roots. Therefore cryopreservation and sectioning needs to be optimized depending on the plant species, organ and tissue type of interest.

LMPC was performed to obtain tissue-specific samples as outlined in Figure 1. The stepwise process of sample collection from cryosectioned stem material is illustrated in Figure 2. First, vascular bundles were marked and thereby selected for excision by utilizing the P.A.L.M. specialized imaging software (Figure 2a). The cutting was then performed by a focused laser beam (Figure 2b), while the final tissue collection into the cap of a microfuge tube was achieved by a defocused laser pulse (Figure $2 \mathrm{c}$ and $2 \mathrm{~d}$ ). The lower limit of the tissue size that can be collected depends on the magnification and the minimal width of the laser beam which is in the range of $1 \mu \mathrm{m}$. In principle, LMPC can be used to isolate a few [19] and even single cells that are resolved e.g. in $40 \times$ magnification (data not shown). The cap was filled with ethanol to inactivate metabolic enzymes during sample collection. This ethanol had to be refilled every 10 min due to evaporation of the solvent, since the collection of a sample consisting of 100 vascular bundles required approximately one hour. After collecting all vascular bundles from a section, the remnant sections without vascular bundles were scraped off into ethanol using a scalpel.

While there are studies demonstrating metabolite measurements in single individual or only a few plant cells, the resulting small sample volumes limited the subsequent metabolite analyses to a restricted number of metabolites that could be determined by enzymatic assays $[1,24]$ or capillary electrophoresis $[4,5]$. These approaches allow the determination of sugars or amino acids with extreme sensitivity but require expertise that is only accessible in a few specialized labs. By employing GC-TOF MS, we intended to take advantage of a well-established analytical standard method that, although less sensitive than the methods described above and not suitable to measure metabolites in individual cells, has the advantage of allowing to comprehensively profile a variety of compounds from different classes simultaneously $[25,26]$. Moreover, GC MS-based platforms for comprehensive metabolite analysis are standard techniques accessible in many labs. 

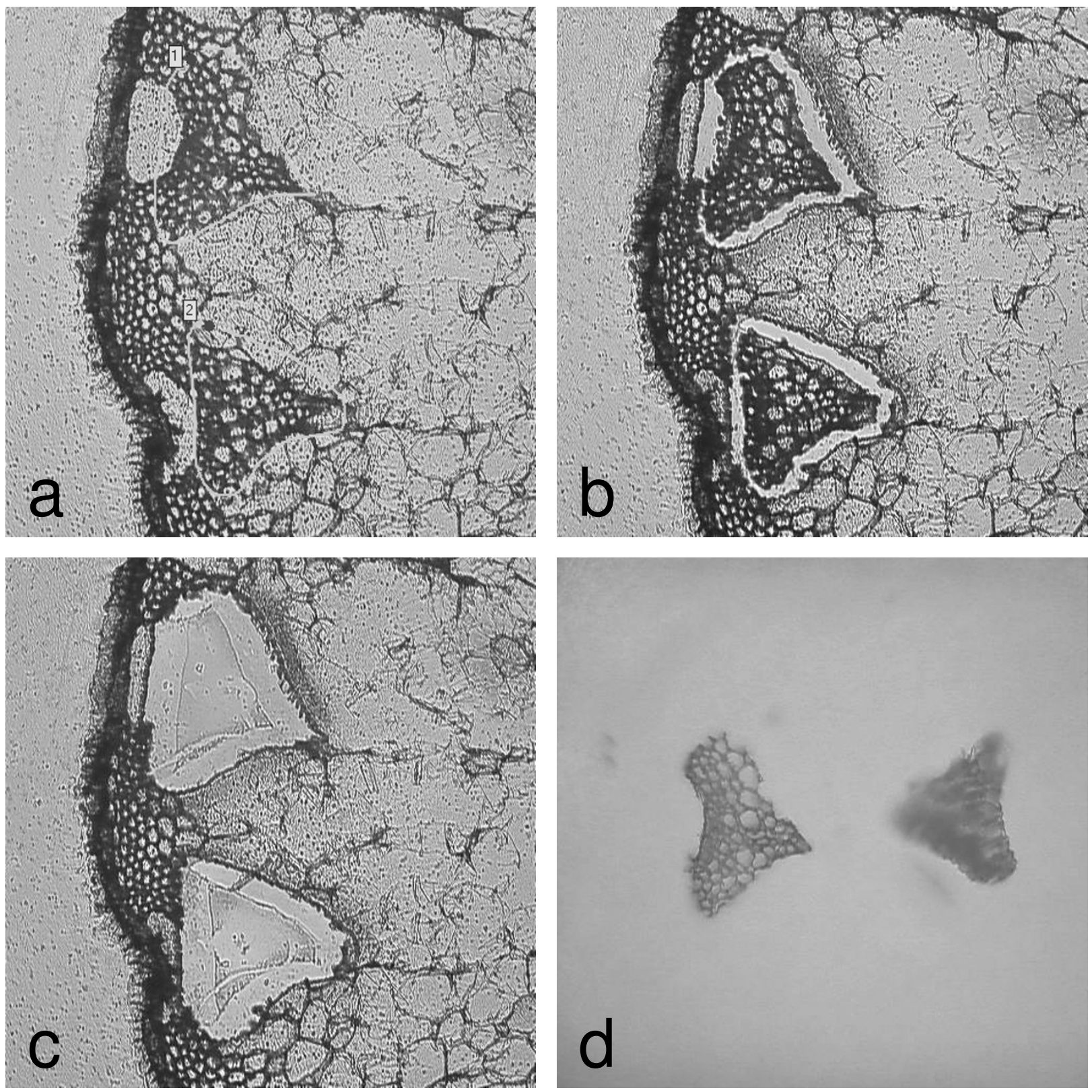

\section{Figure 2}

Laser microdissection. The process of laser microdissection coupled to laser pressure catapulting (LMPC) for collecting vascular bundles from $30 \mu \mathrm{m}$ thick cross sections obtained after freezing and cryosectioning $A$. thaliana stems. (a) Vascular bundles are selected on the computer screen. (b) The laser beam cuts along the markings. (c) The cut cells of interest are catapulted off the slide by a defocused laser pulse and (d) are collected into a cap of a microfuge tube.

\section{Metabolite profiling}

Dealing with such comparably small sample sizes as obtained by LMPC increases the danger of unwanted con- taminations. Initial experiments using untreated plastic reaction tubes during all steps from tissue collection to derivatization led to GC-MS spectra from blanks that not 
Table I: List of metabolites influenced by the sample preparation procedure. Metabolite amounts in stem cross sections. To analyze the influence of tissue processing and laser microdissection on metabolite profiles, complete fresh cryosections and sections after drying and laser microdissection (consisting of vascular bundles and the remaining tissue) were compared. Metabolites with significant differences $(P<0.05)$ in cryosections and laser-microdissected sections $(>1.5)$ are listed.

\begin{tabular}{ccc}
\hline Metabolite & CAS & $\begin{array}{c}\text { Ratio of fresh cryosections vs. complete } \\
\text { laser microdissected sections }\end{array}$ \\
\hline glycerol & $56-81-5$ & 0.6 \\
urea & $57-13-6$ & 0.6 \\
lauric acid & $143-07-7$ & 0.6 \\
linoleic acid & $60-33-3$ & 1.6 \\
succinic acid & $110-15-6$ & 1.7 \\
myo-inositol & $87-89-8$ & 1.7 \\
shikimic acid & $138-59-0$ & 2.0 \\
ethanolamine & $141-43-5$ & 2.5 \\
gamma-aminobutyric acid & $56-12-2$ & 2.5 \\
glucose & $50-99-7$ & 3.9 \\
dehydroascorbic acid & $490-83-5$ & 8.5 \\
\hline
\end{tabular}

only contained the expected artificial peaks resulting from derivatization and column bleeding, but also unexpected metabolite peaks as additional contaminants. The use of reaction tubes from different suppliers resulted in dozens of contaminant peaks in all method blank chromatograms. As a consequence, reaction tubes for all further experiments $(0.5 \mathrm{ml}$ plastic reaction tubes for LMPC as well as $0.2 \mathrm{ml}$ glass vials for GC-MS derivatization) were washed twice with distilled water and dried. Pipette tips were rinsed once with ethanol directly before use. After sample collection, vortexing and centrifugation, supernatants were transferred to glass vials where the derivatization was carried out. These precautions drastically improved the quality of blanks and were essential for metabolite profiling of small sample amounts.

Next, the influence of the sample preparation procedure on the metabolite composition was investigated. To this end we compared samples that were (a) dissolved in ethanol directly after cryosectioning or (b) cut, transferred to slides, stored at $4^{\circ} \mathrm{C}$, and used for LMPC. As expected, some differences in the metabolite profiles of the two sample types were observable: 11 of 72 metabolites identified in measurements from 5 complete stem cross sections (10 replicates) appeared to be sensitive to the sample preparation procedure. These changes were statistically significant $(\mathrm{P}<0.05)$ and showed an at least 1.5 fold increase or decrease in LMPC samples as compared to cryosectioned control samples (Table 1). These observed changes are probably caused by biological and chemical processes during storage, processing and microdissection, since all these steps were carried out at room temperature without air exclusion. Therefore, samples have to run through identical procedures to allow comparisons of metabolite levels. Absolute quantities of certain metabo- lites have to be treated with caution. Dehydroascorbate (the oxidized form of vitamin C), for example, was found to be strongly diminished by the tissue preparation process (Table 1), putatively due to oxidation by air. In LMPC collected vascular bundles and sections without vascular bundles, dehydroascorbate was completely absent.

For tissue-specific GC-TOF MS measurements, we prepared stem cross sections of five A. thaliana plants and collected by LMPC five replicates of about 100 vascular bundles $(\sim$ 5,000 cells) from each plant into ethanol. Additionally, 10 of the remaining vascular bundledepleted sections from each plant were scraped off the slides and also collected into ethanol. The supernatants were dried, derivatized with MSTFA and subjected to GCTOF MS metabolite profiling. Due to the limited sample amounts available, derivatization of the metabolites was done in a volume of only $10 \mu \mathrm{l}$. For the same reason, the injection was carried out without sample wash steps.

\section{Data evaluation}

Using the GC-TOF MS approach, 68 metabolites could be reliably identified in vascular bundles and 65 in sections without vascular bundles. This number of identified metabolites is reasonable considering the small number of cells $(\sim 5,000)$ used for the measurements. The obtained data sets were investigated in more detail to find out differences and similarities in the metabolic profiles from vascular bundles and the surrounding tissue. First, we carried out a principal component analysis (PCA) to see if logical grouping in the data set could be related to maximum variance. This unsupervised multivariate data analysis generates new variables, principal components (PC), that attempt to express the overall variance in the original data. When plotting the tissue-specific metabolite 


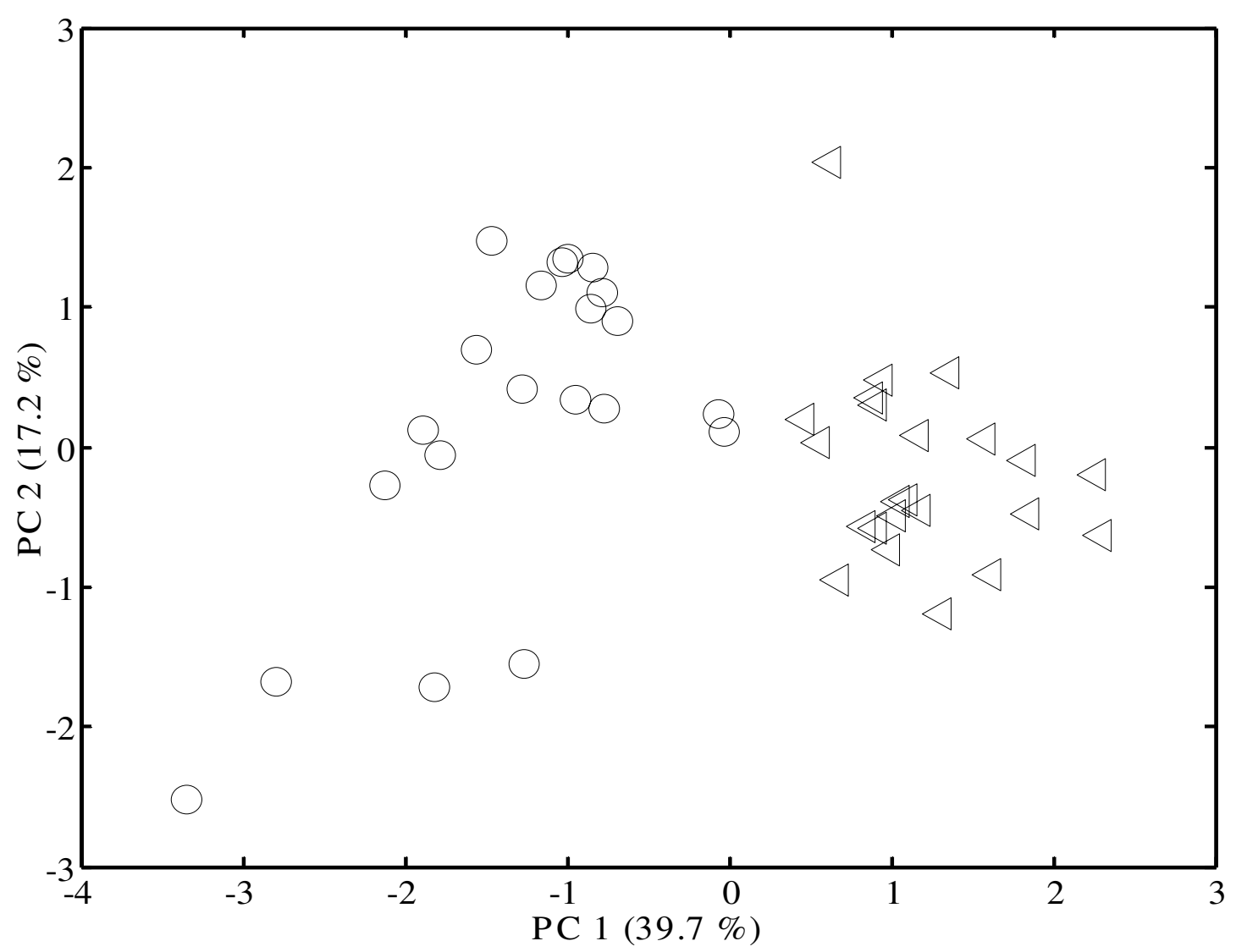

\section{Figure 3}

Statistical evaluation of the metabolite data.Principal Components Analysis (PCA) of metabolite samples generated from $A$. thaliana stem tissue. The PCA score plot for principal component I (PCI) versus principal component 2 (PC2) is presented. The circles represent microdissected vascular bundle tissues ( 21 samples) whilst the triangles are samples from sections without vascular bundles (23 samples).

data, it was immediately obvious that vascular bundles and sections without vascular bundles were well separated and had their own distinct metabolite profiles (Figure 3), indicating that the localization of metabolites was retained during sample processing.

Student t-test comparisons between the data sets revealed that about half of the identified metabolites were significantly different and either enriched or depleted in vascular bundles compared to sections without vascular bundles (Table 2), including six metabolites which were shown to be sensitive to the sample preparation procedure (Table 1). Figure 4 shows examples of chromatograms of vascular bundles and sections without vascular bundles for the mass to charge ratio $(\mathrm{m} / \mathrm{z}) 217$. This ion trace is used to look at sugars and sugar alcohols. The insets (Figures $4 \mathrm{a}$ and $4 \mathrm{~b}$ ) illustrate examples of metabolites being enriched and depleted, respectively, in vascular bundles. Seventeen metabolites were significantly depleted in vascular bundles, while 16 metabolites were enriched in vascular bundles and three metabolites, oxoglutarate, glyceraldehyde and glycerone, were even exclusively found in this tissue type. We are not aware of anything in the literature that would account for these metabolites being exclusively localized to vascular bundles.

Sugars accounted for one class among the metabolites with tissue dependent differences. While reducing sugars like glucose, fucose and fructose were depleted in vascular tissue, the non-reducing sugars sucrose and raffinose were enriched. This distribution of sugars is characteristic for 
Table 2: Metabolites differentially concentrated in vascular bundles and sections without vascular bundles. Metabolites that were differentially concentrated in vascular bundles and sections without vascular bundles (with $P<0.05$ and ratio $<0.67$ or $>1.5$ ) are listed. vb: found only in vascular bundles, ** metabolites which appear to be sensitive to the sample preparation procedure (see Table I).

\begin{tabular}{|c|c|c|}
\hline Metabolite & CAS & $\begin{array}{l}\text { Ratio of vascular bundles vs. sections } \\
\text { without vascular bundles }\end{array}$ \\
\hline stigmasterol & $83-48-7$ & 0.1 \\
\hline gamma-aminobutyric acid** & $56-12-2$ & 0.3 \\
\hline ethanolamine ${ }^{* *}$ & $|4|-43-5$ & 0.3 \\
\hline galactose & $59-23-4$ & 0.4 \\
\hline fucose & $634-74-2$ & 0.4 \\
\hline linolenic acid & $463-40-1$ & 0.4 \\
\hline glucose $e^{* *}$ & $50-99-7$ & 0.4 \\
\hline fructose & $57-48-7$ & 0.4 \\
\hline phenylalanine & $63-91-2$ & 0.5 \\
\hline linoleic acid** & $60-33-3$ & 0.5 \\
\hline leucine & $61-90-5$ & 0.5 \\
\hline benzoic acid & $65-85-0$ & 0.6 \\
\hline urea** & $57-13-6$ & 0.6 \\
\hline isoleucine & $73-32-5$ & 0.6 \\
\hline valine & $72-18-4$ & 0.6 \\
\hline lignoceric acid & $557-59-5$ & 0.6 \\
\hline mannose & $3458-28-4$ & 0.7 \\
\hline heptadecanoic acid & $506-12-7$ & 1.6 \\
\hline aspartic acid & $56-84-8$ & 1.7 \\
\hline malic acid & $97-67-6$ & 1.7 \\
\hline adipic acid & $124-04-9$ & 1.8 \\
\hline proline & $147-85-3$ & 1.9 \\
\hline sucrose & $57-50-1$ & 1.9 \\
\hline lauric acid** & 143-07-7 & 1.9 \\
\hline raffinose & $512-69-6$ & 2.1 \\
\hline isocitric acid & $320-77-4$ & 2.2 \\
\hline oleic acid & || $2-80-\mid$ & 2.3 \\
\hline myristic acid & $544-63-8$ & 2.4 \\
\hline glycine & $56-40-6$ & 2.8 \\
\hline 6-amino caproic acid & $60-32-2$ & 3.5 \\
\hline citric acid & $77-92-9$ & 3.7 \\
\hline trans-squalene & III-02-4 & 4.4 \\
\hline phosphate & $14265-44-2$ & 5.2 \\
\hline oxoglutarate & $328-50-7$ & $\mathrm{vb}$ \\
\hline glyceraldehyde & $367-47-5$ & $\mathrm{vb}$ \\
\hline glycerone & $96-26-4$ & $\mathrm{vb}$ \\
\hline
\end{tabular}

phloem sap that probably accounts for a great portion of vascular bundle metabolites.

A further class of compounds that showed different levels in vascular bundles compared to the surrounding tissue was amino acids. From this group glutamate, aspartate and glutamine are the major amino acids distributed through the phloem tubes in A. thaliana [27] and therefore could be expected to be enriched in vascular bundles. In this study, we found only aspartate significantly enriched in vascular bundles compared to the surrounding tissue while glutamate and glutamine were indeed abundant in vascular bundles, but similar levels were also detected in sections without vascular bundles. These find- ings are unlikely to be caused by the sample treatment because none of these amino acids belonged to the group of substances influenced by the sample processing procedure (Table 1).

\section{Conclusion}

This study demonstrates for the first time that laser microdissection can be successfully applied to analyze the spatial distribution of metabolites within plant tissues. The application of a suitable sample preparation protocol, omitting any solute exchange steps, followed by LMPC makes metabolite profiling of 100 vascular bundles, equivalent to only 5,000 cells, by standard GC-TOF MS measurements feasible. In principle this method should 


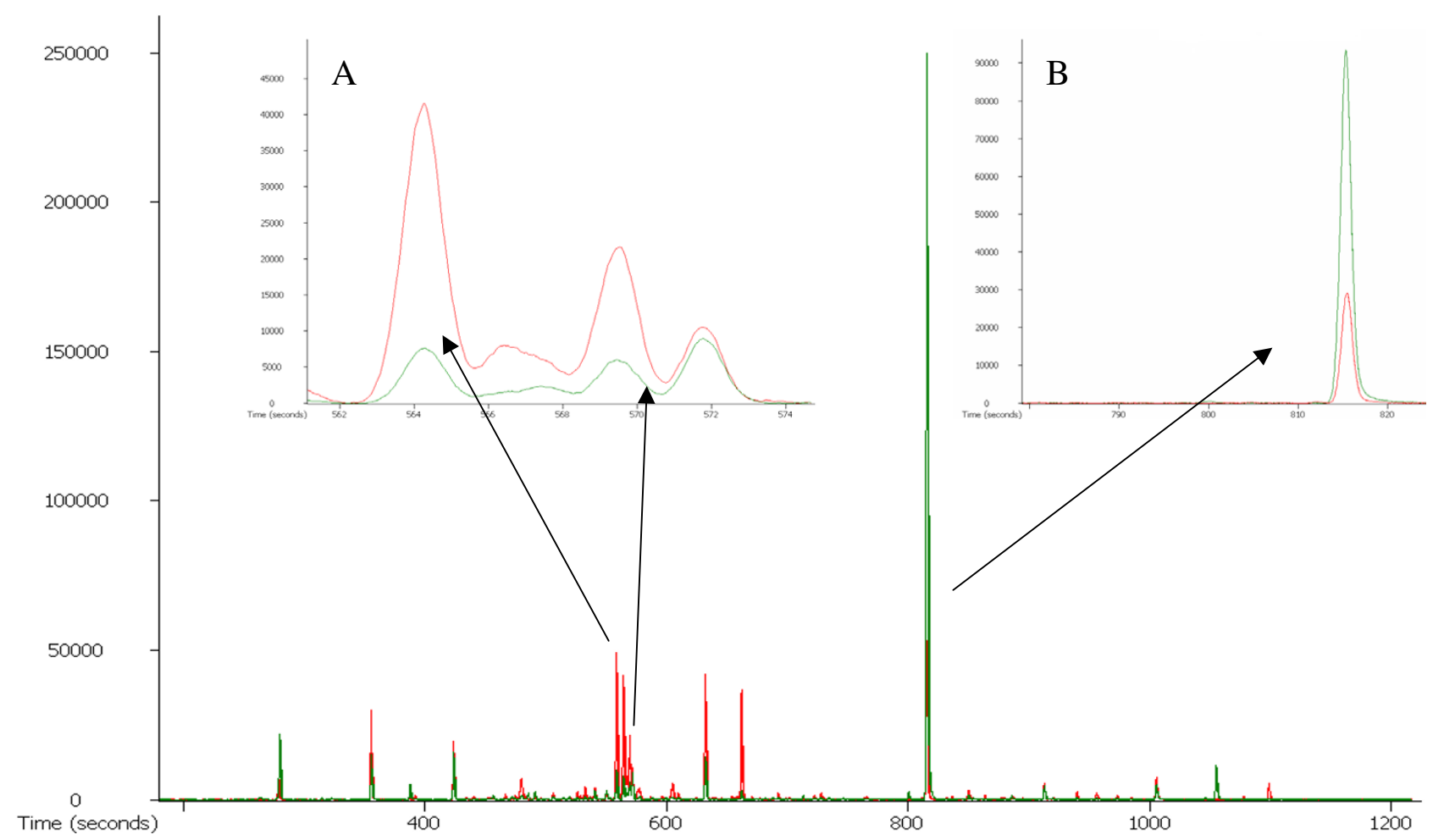

\section{Figure 4}

Example chromatogram. Entire chromatogram for $\mathrm{m} / \mathrm{z} 217$, an ion trace for sugars and sugar alcohols. The vascular bundle sample is shown in green and the sample without vascular bundle in red. (a) shows an example of depleted sugars in vascular bundles - fructose (retention time 564.19 s) and glucose (retention time 569.419 s) while (b) illustrates the zoomed-in sucrose peak (retention time $815.369 \mathrm{~s}$ ) being enriched in vascular bundles.

be applicable to a wide range of cells and tissues given that sufficiently good morphology is obtained following the introduced cryosectioning procedure. In combination with the previously described RNA and protein expression profiling, cell type-specific metabolite profiling will allow a comprehensive characterization of distinct tissues, an essential step towards a thorough understanding of gene functions.

\section{Methods}

Preparation of tissue sections and laser microdissection Arabidopsis thaliana (Col-0) plants were grown on soil in a growth chamber under short day conditions $(8 \mathrm{~h}$ light, $20^{\circ} \mathrm{C}$ and $16 \mathrm{~h}$ dark, $16^{\circ} \mathrm{C}, 75 \% \mathrm{RH}$ ) for four weeks and then in the greenhouse under long day conditions $(16 \mathrm{~h}$ light, $20^{\circ} \mathrm{C}, 60 \% \mathrm{RH}$ and $8 \mathrm{~h}$ dark, $\left.18^{\circ} \mathrm{C}, 75 \% \mathrm{RH}\right)$. Stems of 6 week-old plants were frozen in liquid nitrogen and transferred to a cryostat (Microm, Waldorf, Germany) cooled to $-30^{\circ} \mathrm{C}$. Using a scalpel, $15 \mathrm{~mm}$-long stem pieces were cut. Stem pieces were glued onto the sample plate by employing Neg-50 (Richard-Allan Scientific, Kalamazoo, MI, USA), a water-soluble frozen section medium. Using the cryostat, $30 \mu \mathrm{m}$ sections were cut and transferred to glass slides where they dried within seconds at room temperature.

For microdissection, the P.A.L.M. Laser Microbeam System (Bernried, Germany) was employed. This system consists of a low heat UV (337 nm nitrogen) laser and an inverted microscope. Cells were selected using the graphics tools of the P.A.L.M. RoboSoftware. After selection, vascular bundles were isolated by the laser microbeam and afterwards collected by laser pressure catapulting into the lid of a $0.5 \mathrm{ml}$ reaction tube (Eppendorf, Hamburg, Germany) filled with $50 \mu$ ethanol (Merck, Darmstadt, Germany), placed in a holder closely above the slide. After collection of vascular bundles, the remaining sections were scraped off the slides using a scalpel into ethanol (subsequently called sections without vascular bundles). The cell numbers were estimated from the number of 
vascular bundles collected and the cell number counted in one representative vascular bundle.

Both types of samples were vortexed and centrifuged for 5 min at $14.000 \mathrm{rpm}$. Supernatants were collected in $0.2 \mathrm{ml}$ glass vials (Chromacol, Herts, United Kingdom) and vacuum dried. All used reaction tubes, including their lids, were washed twice with distilled water and dried before use. More details of quality control procedures during sample preparation are provided in the text main body. Five parallel plants were employed. From each plant, five replicates of 100 vascular bundles and $5 \mathrm{sec}-$ tions without vascular bundles were used for metabolite analysis. As negative controls, ethanol without microdissected material was processed in parallel to the samples.

\section{Metabolite profiling}

For GC-TOF MS (Leco Pegasus II GC-TOF mass spectrometer; Leco, St. Joseph, MI, USA) analysis, the vacuum dried samples were dissolved in $1 \mu \mathrm{l}$ methoxamine hydrochloride $(20 \mathrm{mg} / \mathrm{ml}$ pyridine $)$ and incubated at $30^{\circ} \mathrm{C}$ for 90 min with continuous shaking. Then $9 \mu \mathrm{l}$ of $\mathrm{N}$-methyl-Ntrimethylsilyltrifluoroacetamid (MSTFA) were added to derivatize polar functional groups at $37^{\circ} \mathrm{C}$ for $30 \mathrm{~min}$. The derivatized samples were stored at room temperature for 120 min before injection. GC-TOF MS analysis was performed on an HP 5890 gas chromatograph with tapered, deactivated split/splitless liners containing glass wool (Agilent, Böblingen, Germany) and $1.5 \mu \mathrm{l}$ splitless injection at $230^{\circ} \mathrm{C}$ injector temperature. Before each injection, the liner was rinsed with a pure MSTFA injection $(1 \mu \mathrm{l})$. Sample injection was carried out without sample wash steps due to the limited amount of total sample volume. The GC was operated at constant flow of $2 \mathrm{ml} / \mathrm{min}$ helium and a $30 \mathrm{~m} 0.32 \mathrm{~mm}$ id $0.25 \mu \mathrm{m}$ MDN35 column (Macherey-Nagel, Düren, Germany). The temperature gradient started at $80^{\circ} \mathrm{C}$, was held isocratic for $2 \mathrm{~min}$, and subsequently ramped at $15^{\circ} \mathrm{C} / \mathrm{min}$ to a final temperature of $330^{\circ} \mathrm{C}$ which was held for $6 \mathrm{~min}$. Twenty spectra per second were recorded between $\mathrm{m} / \mathrm{z}$ 85-500. Peak identification and quantification were performed using the Pegasus software package ChromaTOF 1.61 (Leco). A reference chromatogram was defined that had a maximum of detected peaks over a signal/noise threshold of 5 and used for automated peak identification based on mass spectral comparison to a standard NIST 98 library and own customized mass spectral libraries. Automated assignments of unique fragment ions for each individual metabolite were taken as default as quantifiers, and manually corrected where necessary. All known artifact peaks caused by column bleeding or phtalates and polysiloxanes derived from MSTFA hydrolysis were manually identified and removed from the results table. Remaining metabolite data were normalized to the total area of all detected metabolites and log-transformed. Due to the utmost requirements of low sample volumes and chemical background, no further internal standards were added. Statistical analyses were performed using Matlab version 6.5 (The MathWorks, MA, USA).

\section{Competing interests}

The author(s) declare that they have no competing interests.

\section{Authors' contributions}

MS carried out the optimization of sample preparation for GC-TOF MS measurements, collected samples by LMPC, participated in data evaluation and drafted the manuscript. RM participated in LMPC sample collection, GCTOF MS measurements and data analysis. OF participated in GC-TOF MS optimization, data evaluation, and manuscript drafting. JK conceived of the study, arranged its design and coordination and was involved in manuscript writing. All authors read and approved the final manuscript.

\section{Acknowledgements}

The authors thank Carola Kuhn and Professor Martin Steup from the University of Potsdam for supporting the cryostat work.

\section{References}

I. Tomos AD, Hinde P, Pritchard J, Fricke W: Microsampling and measurements of solutes in single cells. Plant cell biology: a practical approach Edited by Harris N, Oparka KJ Oxford: Oxford University Press 1994:297-314.

2. Andersson $\mathrm{H}$, van den Berg $\mathrm{A}$ : Microtechnologies and nanotechnologies for single-cell analysis. Current Opinion in Biotechnology 2004, I 5:44-49.

3. Brandt S, Kehr J, Walz C, Imlau A, Willmitzer L, Fisahn J: A rapid method for detection of plant gene transcripts from single epidermal, mesophyll and companion cells of intact leaves. Plant Journal 1999, 20:245-250.

4. Arlt K, Brandt S, Kehr J: Amino acid analysis in five pooled single plant cell samples using capillary electrophoresis coupled to laser-induced fluorescence detection. Journal of Chromatography A 2001, 926:319-325.

5. Tomos AD, Sharrock RA: Cell sampling and analysis (SiCSA): metabolites measured at single cell resolution. Journal of Experimental Botany 2001, 52:623-630.

6. Schuetze K, Lahr G: Identification of expressed genes by lasermediated manipulation of single cells. Nat Biotech 1998, I 6:737-742.

7. Emmert-Buck M, Bonner R, Smith P, Chuaqui R, Zhuang Z, Goldstein $S$, Weiss R, Liotta L: Laser capture microdissection. Science 1996, 274:998-100।.

8. Wittliff JL, Erlander MG: Laser capture microdissection and its applications in genomics and and proteomics. Methods in Enzymology 2002, 356: I 2-25.

9. Westphal G, Friedemann RB, Wellmann A, Wernert N, Wollscheid V, Becker B, Vogt T, Knuchel R, Stolz W, Schutze K: Noncontact laser catapulting: a basic procedure for functional genomics and proteomics. Methods in Enzymology 2002, 356:80-99.

10. Kerk NM, Ceserani T, Tausta SL, Sussex IM, Nelson TM: Laser capture microdissection of cells from plant tissues. Plant Physiology 2003, 132:27-35.

II. Asano T, Masumura T, Kusano H, Kikuchi S, Kurita A, Shimada H, Kadowaki K: Construction of a specialized cDNA library from plant cells isolated by laser capture microdissection: toward comprehensive analysis of the genes expressed in the rice phloem. Plant Journal 2002, 32:40I-408.

12. Nakazono M, Qiu F, Borsuk LA, Schnable PS: Laser-capture microdissection, a tool for the global analysis of gene expression in 
specific plant cell types: identification of genes expressed differentially in epidermal cells or vascular tissues of maize. Plant Cell 2003, 15:583-596.

13. Schad M, Lipton MS, Giavalisco P, Smith RD, Kehr J: Evaluation of 2-DE and LC-MS/MS for tissue-specific protein profiling of laser microdissected plant samples. Electrophoresis 2005.

14. Ahram M: Evaluation of ethanol-fixed, paraffin-embedded tissues for proteomic applications. Proteomics 2003, 3:4I3.

15. Gillespie JW, Best CJM, Emmert-Buck MR: Evaluation of non-formalin tissue fixation for molecular profiling studies. American Journal of Pathology 2002, 160:449-457.

16. Ge H, Gong X, Tang CK: Evidence of high incidence of EGFRvIII expression and coexpression with EGFR in human invasive breast cancer by laser capture microdissection and immunohistochemical analysis. International Journal of Cancer 2002, 98:357-36I.

17. Upson JJ, Stoyanova R, Cooper HS, Patriotis C, Ross EA, Boman B, Clapper ML, Knudson AG, Bellacosa A: Optimized procedures for microarray analysis of histological specimens processed by laser capture microdissection. Journal of Cellular Physiology 2004, 20I:366-373.

18. Kehr J: High resolution spatial analysis of plant systems. Current Opinion in Plant Biology 2001:197-201.

19. Kehr J: Single cell technology. Current Opinion in Plant Biology 2003, $6: 1-5$.

20. Burgemeister R, Gangnus R, Haar B, Schütze K, Sauer U: High quality RNA retrieved from samples obtained by using LMPC (Laser Microdissection and Pressure Catapulting) technology. Pathology Research and Practice 2003, 199:43I-436.

21. Brandt S, Walz C, Schad M, Pavlovic N, Kehr J: A simple, chisel assisted mechanical microdissection system for harvesting homogenous plant tissue suitable for the analysis of nucleic acids and proteins. Plant Molecular Biology Reporter 2003, 21:4I7-427.

22. Fellenberg J, Krauthoff A, Pollandt K, Delling G, Parsch D: Evaluation of the predictive value of Her-2/neu gene expression on osteosarcoma therapy in laser-microdissected paraffinembedded tissue. Laboratory Investigation 2004, 84: I |3-I2I.

23. Kim JO, Kim HN, Hwang MH, Shin HI, Kim SY, Park RW, Park EY, Kim IS, Wijnen AJ, Stein JL, Lian JB, Stein GS, Choi JY: Differential gene expression analysis using paraffin-embedded tissues after laser microdissection. Journal of Cellular Biochemistry 2003, 90:998-1006.

24. Kehr J, Hustiak F, Walz C, Willmitzer L, Fisahn J: Transgenic plants changed in carbon allocation pattern display a shift in diurnal growth pattern. Plant Journal 1998, 16:497-503.

25. Weckwerth W, Loureiro ME, Wenzel K, Fiehn O: Differential metabolic networks unravel the effects of silent plant phenotypes. PNAS 2004, 101:7809-78|4.

26. Weckwerth W, Wenzel K, Fiehn O: Process for the integrated extraction, identification and quantification of metabolites, proteins and RNA to reveal their co-regulation in biochemical networks. Proteomics 2004, 4:78-83.

27. Zhu X, Shaw PN, Pritchard J, Newbury J, Hunt EJ, Barrett DA Amino acid analysis by micellar electrokinetic chromatography with laser-induced fluorescence detection: Application to nanolitre-volume biological samples from Arabidopsis thaliana and Myzus persicae. Electrophoresis 2005, 26:91 I-919.
Publish with Biomed Central and every scientist can read your work free of charge

"BioMed Central will be the most significant development for disseminating the results of biomedical research in our lifetime. "

Sir Paul Nurse, Cancer Research UK

Your research papers will be:

- available free of charge to the entire biomedical community

- peer reviewed and published immediately upon acceptance

- cited in PubMed and archived on PubMed Central

- yours - you keep the copyright

Submit your manuscript here:

http://www.biomedcentral.com/info/publishing_adv.asp
BioMedcentral 